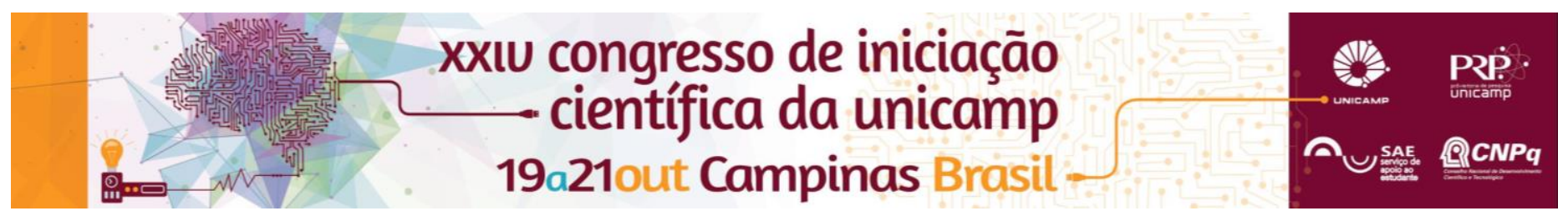

\title{
Investigação experimental da influência do bicarbonato de sódio na polimerização em emulsão e miniemulsão
}

\section{Juliano Dognani Castro, Liliane Maria Ferrareso Lona}

\section{Resumo}

Com o intuito de viabilizar a polimerização controlada via NMRP (polimerização radicalar viva mediada por nitróxidos) a temperaturas abaixo de $100^{\circ} \mathrm{C}$, este projeto de iniciação científica verifica o efeito de se utilizar bicarbonato de sódio no meio reacional, que, em função da dinâmica do laboratório, esta pesquisa iniciou com a síntese em sistemas em miniemulsão.

\section{Palavras-chave}

Polimerização, reator, miniemulsão.

\section{Introdução}

Dentre as técnicas para produção de polímeros, a polimerização em sistemas heterogêneos (em emulsão e em miniemulsão) é muito importante. A grande vantagem dessas técnicas é que elas são conduzidas em água. Em nosso grupo de pesquisa, Montezuma (2011) conseguiu desenvolver o processo NMRP em emulsão utilizando como agente controlador o TEMPO em temperaturas inferiores a $100^{\circ} \mathrm{C}$ (Lona et al., 2011, Montezumaet al., 2012). O composto TEMPO se tornou um dos nitróxidos mais utilizados, devido à sua estabilidade e sua compra ser mais acessível.

Nesse presente projeto foram realizados experimentos em emulsão e miniemulsão em temperaturas inferiores a $100^{\circ}$ C utilizando bicarbonato de sódio, a fim de se entender melhor os fatores que afetam o processo.

O objetivo deste projeto é sintetizar polímeros controlados a baixas temperaturas e em sistemas heterogêneos, através da técnica NMRP usando TEMPO como controlador. Para atingir este objetivo, será verificada a influência da adição de bicarbonato de sódio no sistema reacional.

\section{Resultados e Discussão}

O monômero utilizado foi o estireno e o iniciador utilizado, na polimerização em miniemulsão, foi o 2,2' - azobisisobutironitrila (AIBN). A preparação das fases orgânica (estireno) e aquosa foi feita independentemente e, posteriormente, homogeneizadas (formação da miniemulsão) e, por fim, adicionadas ao reator com tanque agitado de 1 litro de capacidade à temperatura de $90^{\circ} \mathrm{C}$.

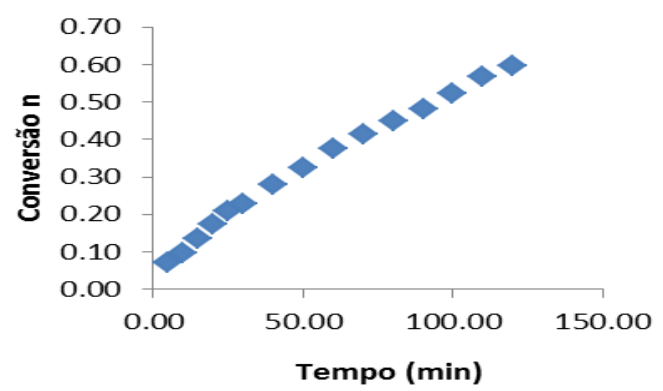

Figura 1. Conversão versus tempo (reação em miniemulsão convencional sem $\mathrm{NaHCO} 3)$.
Através de coletas ao longo do período de duas horas e do conhecimento de algumas propriedades provindas da literatura, foi possível obter pontos de conversão segundo o tempo de retirada da amostra do reator (Figura 1).

Abaixo, a Figura 2 apresenta a distribuição monomodal dos diâmetros das partículas relacionando cada um com sua respectiva conversão.

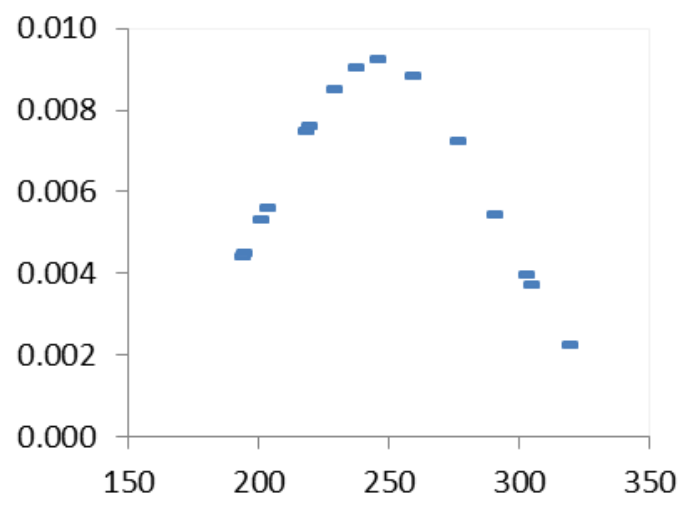

Figura 2. Distribuição do diâmetro das partículas (reação em miniemulsão convencional sem $\mathrm{NaHCO} 3$ ).

\section{Conclusões}

Os resultados obtidos estão coerentes com os encontrados na literatura e com a teoria sobre polimerização em miniemulsão.

\section{Agradecimentos}

Principalmente, à Universidade Estadual de Campinas e à Samara Boaventura Moraes.

Lona, L. M. F., Montezuma, G. G. C., Contant, S., 2011. Processo de Polimerização Controlada do Estireno em Emulsão, uso do mesmo e Produto Obtido pelo dito Processo. Patente depositada pela Inova/Unicamp, protocolo: 018110045780, data: 24/11/2011.

Montezuma, G. G. C., 2011. Investigação Experimental da Polimerização do Estireno Mediada por TEMPO (2,2,6,6-tetrametil-1-piperidiniloxi) em Emulsão. Dissertação de Mestrado, Faculdade de Engenharia Química, Unicamp.

Montezuma, G. G. C., Contant, S., Lona, L. M. F., 2012. Emulsion Polymerization of Styrene Mediated by TEMPO (2,2,6,6-tetramethylpiperidin-1-oxyl) at Low Temperature. Macromolecular ReactionEngineering. No prelo 2012. 